\title{
Endoscopic treatment of esophageal intramural abscess caused by embedded metal clip: a rare delayed complication of endoscopic submucosal dissection
}
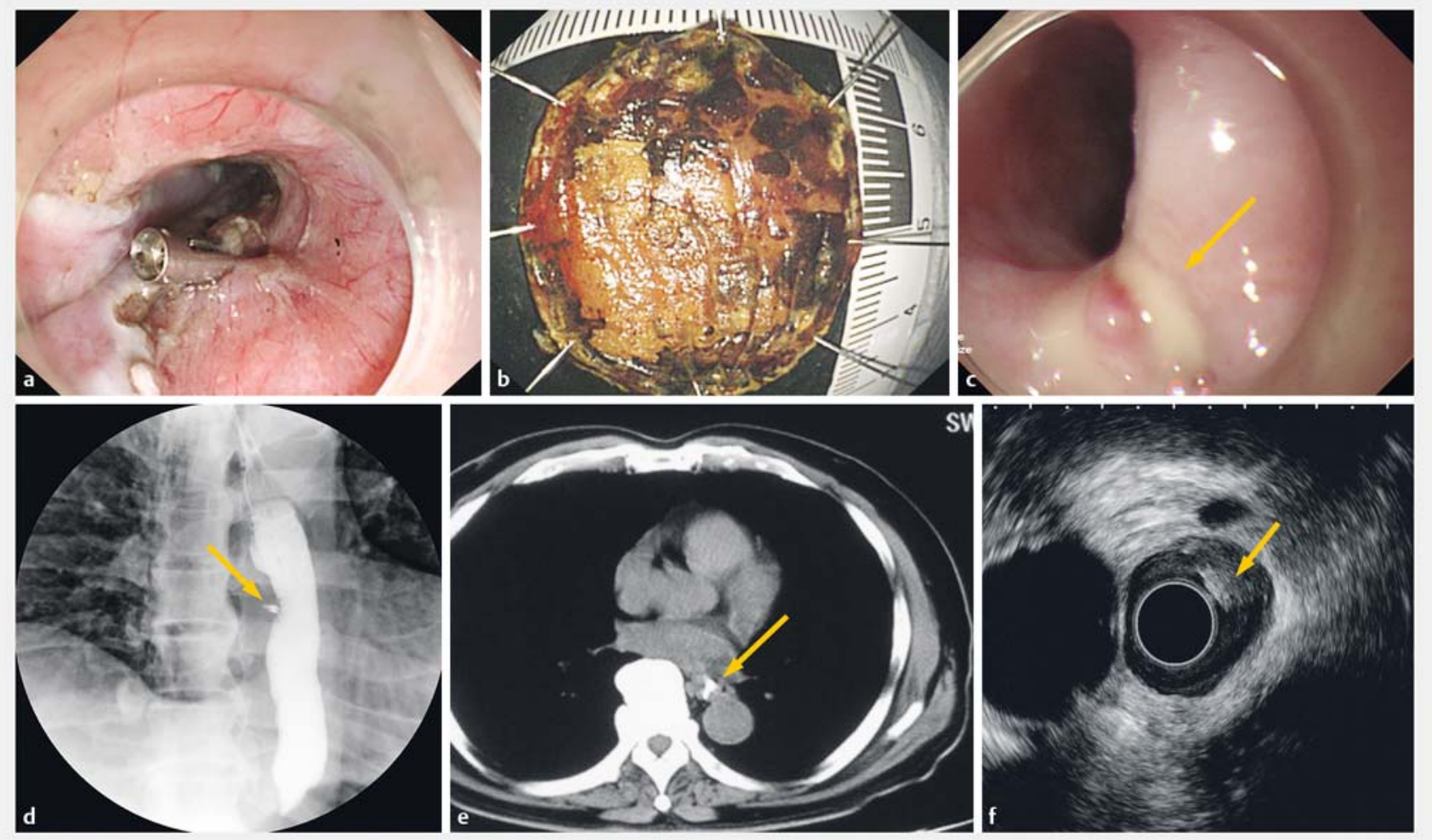

- Fig. 1 An embedded hemoclip at the left wall of the middle esophagus. a Two hemoclips were used to close the small perforation during endoscopic submucosal dissection. $\mathbf{b}$ The resected specimen of early esophageal cancer. $\mathbf{c}$ Endoscopy showed a fistula with outflowing pus in the middle esophagus (yellow arrow). $\mathbf{d}$ Barium contrast radiography showed a metal clip causing outer compression and mimicking esophageal stricture (yellow arrow). e Computed tomography scan showed thickening of the middle esophageal wall and a metal foreign body embedded in the wall (yellow arrow). f Endoscopic ultrasound showed heterogeneous echo occupation of the esophageal wall with local hyperechoic change (yellow arrow).

Endoscopic submucosal dissection (ESD) is indicated for the treatment of superficial digestive tract cancers [1]. Bleeding and perforation are common complications of ESD. Metal clips have often been used for endoscopic closure of mucosal defects or exposed vessels, in order to reduce the risk of complications. After ESD, most metal clips fall off spontaneously.

We present the case of a 61-year-old man who underwent ESD for early esophageal cancer at the left wall of the middle esophagus, with two clips used for endoscopic closure of a small per-

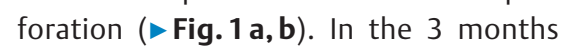

after ESD, the patient complained of nausea and vomiting without fever or chest pain. He was referred to our hospital.

The endoscopic examination showed pus flowing from a fistula in the middle of the esophagus ( $\mathbf{F i g . 1} \mathbf{c}$ ). The patient underwent esophageal barium contrast radiography, which revealed outer compression with a metal clip mimicking an

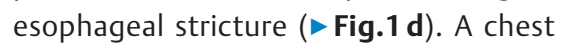
computed tomography scan was then performed, and showed wall thickening in the middle esophagus with a radiodense foreign body of metal density embedded in the wall ( $\mathbf{F i g . 1 e ) . ~ E n d o - ~}$ scopic ultrasound was also performed, and showed heterogeneous echo occupation of the esophageal wall with local hyperechoic change ( $\mathbf{F i g . 1} \mathbf{1}$ ) [2].

For treatment, we performed endoscopic incision of the wall of the esophageal intramural abscess using a DualKnife (Olympus, Tokyo, Japan), which exposed the tip of the embedded clip with outflowing pus. Subsequently, the clip was successfully removed from the esophageal wall using a foreign body forceps ( $\triangleright$ Fig.2a-d, $\triangleright$ Video 1) [3]. The patient was discharged with no further symptoms after 3 days of intravenous antibiotic treatment. 


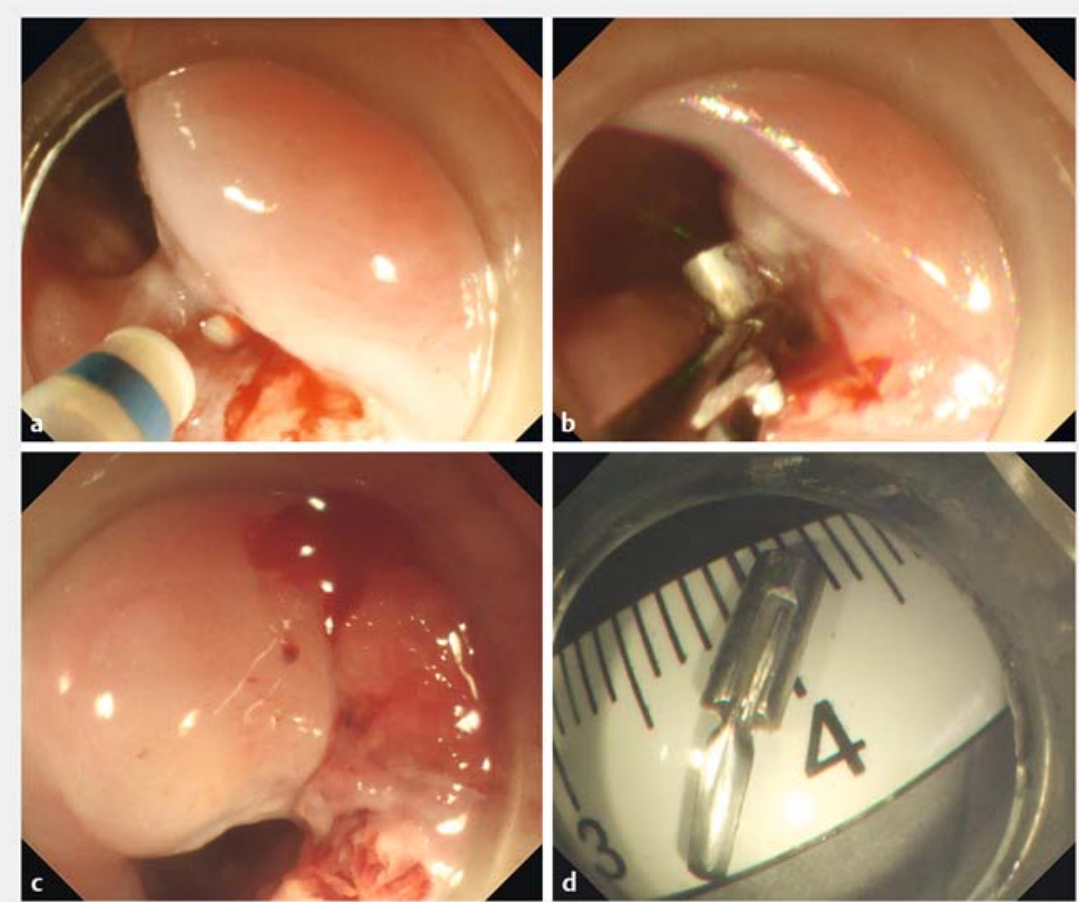

- Fig. 2 Endoscopic retrieval of the clip embedded in the esophageal wall. a Mucosal incision using a DualKnife (Olympus, Tokyo, Japan). b Removal of the clip using a foreign body forceps. $\mathbf{c}$ The wall of the esophageal intramural abscess after clip removal. $\mathbf{d}$ The retrieved clip.

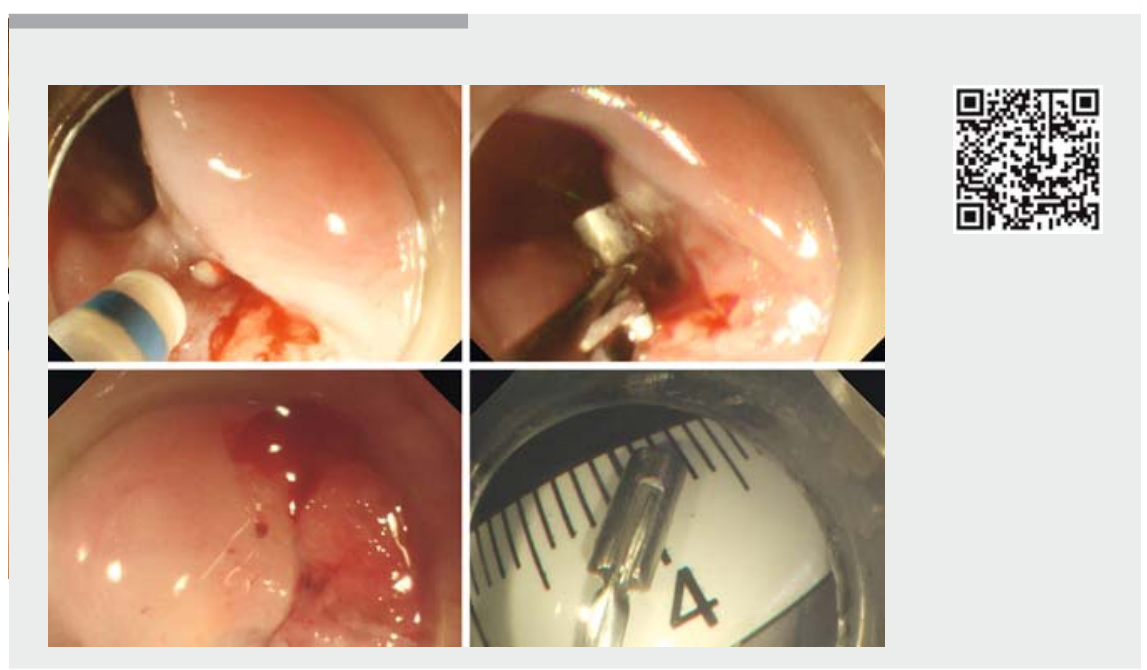

Video 1 Endoscopic retrieval of the embedded clip in the esophageal wall.

Remnant metal clip buried in the esophageal wall after ESD and leading to esophageal intramural abscess is rare. To our knowledge, this is the first report of endoscopic removal of a metal clip that was totally embedded in the esophageal wall.

Endoscopy_UCTN_Code_CPL_1AH_2AZ
The authors

\section{Peng Wang, Feng Liu}

Department of Gastroenterology, Changhai Hospital, Second Military Medical University, Shanghai, China

\section{Corresponding author}

\section{Feng Liu, MD}

Department of Gastroenterology, Changhai Hospital, Second Military Medical University, 168 Changhai Road, Shanghai, 200433,

China

Fax: +86-21-55621735

drliuffeng@hotmail.com

\section{References}

[1] Mavrogenis G, Hochberger J, Deprez P et al. Technological review on endoscopic submucosal dissection: available equipment, recent developments and emerging techniques. Scand J Gastroenterol 2017; 52: 486-498

[2] Rana SS, Bhasin DK, Rao C et al. Endoscopic ultrasound-guided diagnosis and management of an unusual gastric submucosal lesion - gastric wall abscess. Endoscopy 2013; 45 (Suppl. 02): E136-E137

[3] Guo H, Zou X, Li W et al. Successful retrieval of a foreign body embedded in the wall of the piriform sinus by mucosal incision. Endoscopy 2015; 47 (Suppl. 01): E612-E613

\section{Bibliography}

DOI https://doi.org/10.1055/a-0584-6323

Published online: 22.3.2018

Endoscopy 2018; 50: E134-E135

(c) Georg Thieme Verlag KG

Stuttgart · New York

ISSN 0013-726X

\section{ENDOSCOPY E-VIDEOS}

https:/|eref.thieme.de/e-videos

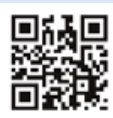

Endoscopy E-Videos is a free access online section, reporting on interesting cases and new techniques in gastroenterological endoscopy. All papers include a high quality video and all contributions are freely accessible online.

This section has its own submission website at

https://mc.manuscriptcentral.com/e-videos 